(80)

\title{
Does Over-Dominance of Bambusa bambos alter the Abundance and Composition of Arbuscular Mycorrhizal Fungal Community?
}

\author{
Millangoda M.G.U.A.*, Madawala H.M.S.P. \\ Department of Botany, Faculty of Science, University of Peradeniya, Sri Lanka \\ *uthpalamillangoda@gmail.com
}

\begin{abstract}
Plants have the potential to modify soil biological properties through root exudates and litter inputs. Bambusa bambos (L) Voss., a native bamboo, has been expanding its range in Intermediate and dry zone forests in Sri Lanka. With synchronised flowering and death cycles, bamboos have shown the potential to modify forest dynamics. No study has been attempted so far to evaluate its impacts on biological properties of forest soils. The current study assessed the impacts of population expansion of B. bambos on arbuscular mycorrhizal fungi (AMF) by conducting a comparative study with the help of bamboo-dominated (BD) and non-bamboo (NB) forest patches in the Intermediate Zone, Sri Lanka. The study sites are located in Moragahakanda in the Central Province of Sri Lanka. Two sites (located $4 \mathrm{~km}$ apart from each other) were selected; one dominated by bamboo (BD) and the other with no bamboo (NB). Eight composite soil samples (from a depth of 0-20 cm) were analysed for soil moisture content (\%) and microbial biomass Carbon (MBC \%). Wet sieving and decanting method was used to quantify the AMF spores. Different morphotypes were identified using spore wall characteristics. The results revealed significantly higher soil moisture in BD than in NB while $\mathrm{MBC} \%$ showed no significant difference. A relatively higher total spore count $(2,923)$ was reported in $\mathrm{BD}$ compared to $\mathrm{NB}(2,776)$. BD forests also demonstrated significantly higher mean spore abundance $(\approx 500 / 100 \mathrm{~g}$ soil $)$ compared to that in NB forests $(\approx 100 / 100 \mathrm{~g}$ soil $)$, with higher relative contribution from largest spores $(125 \mu \mathrm{m})$. The AMF richness was relatively low in BD forest (15) than in NB (18), with 14 morphotypes present in both forest types. Shannon-Wiener index and evenness were relatively higher in NB (2.38 and 0.3) in comparison to BD (2.24 and 0.28). B. bambos has shown the potential to increase the AMF abundance with no impact on its richness and composition. Higher AMF abundance may possibly due to favourable micro-habitat conditions at BD compared to NB. Identification of such changes is crucial to introduce measures for conservation and restoration of these sensitive forests.
\end{abstract}

Keywords: Native bamboos, AMF, Rapid spread, Bambusa bambos, Sri Lanka

Proceedings of the $22^{\text {nd }}$ International Forestry and Environment Symposium 2017 of the Department of Forestry and Environmental Science, University of Sri Jayewardenepura, Sri Lanka 